\title{
The Relationship between Alienation from Learning and Student Needs in Swiss Primary and Secondary Schools
}

\author{
Kaja Marcin, Julia Morinaj, and Tina Hascher \\ University of Bern, Switzerland
}

\begin{abstract}
Previous studies have shown that secondary schools are less successful than primary schools in responding to student needs. Simultaneously, students seem to detach themselves during secondary schooling. Based on this, the present study investigated alienation from learning and its relationship with students' perception of needs support by teachers and peers by analyzing data from 486 primary and 550 secondary school students in Switzerland. Multigroup structural equation modeling was employed to analyze the relevance of each independent variable for alienation from learning within and across the two subsamples. Teacher injustice as an indicator for the teacher-student relationship was significantly associated with alienation from learning for both subsamples, whereas there was a significant effect for competence support only in secondary schools. The findings highlight the importance of just and supportive teachers in preventing students' alienation from learning in school.
\end{abstract}

Keywords: School alienation, autonomy and competence support, social relatedness, teacher (in-)justice, student needs

Der Zusammenhang zwischen Entfremdung vom Lernen und Schülerbedürfnissen in Schweizer Primar- und Sekundarschulen

Zusammenfassung: Forschungsergebnissen zufolge berücksichtigen Sekundarschulen die Bedürfnisse der Schüler_innen weniger gut als Primarschulen. Zugleich distanzieren sich die Jugendlichen zunehmend von der Schule. Entsprechend untersuchte die Studie mit 486 Primarund 550 Sekundarschüler_innen den Zusammenhang zwischen Entfremdung vom Lernen und den Bedürfnissen von Schüler_innen. Multigroup-Strukturgleichungsmodellierung wurde verwendet, um die Relevanz der unabhängigen Variablen für die Entfremdung vom Lernen innerhalb und zwischen den beiden Teilstichproben zu analysieren. Es zeigte sich bei beiden Teilstichproben ein signifikanter Zusammenhang zwischen der Entfremdung vom Lernen und Ungerechtigkeitserfahrungen durch Lehrpersonen, verstanden als Indikator für fehlende soziale Eingebundenheit. Kompetenzunterstützung hingegen konnte nur bei den Sekundarschüler_innen einen signifikanten Anteil der Varianz in der Entfremdung vom Lernen erklären. Die Ergebnisse unterstreichen die Bedeutsamkeit gerechter und unterstützender Unterrichtsgestaltung für die Prävention der Entfremdung vom schulischen Lernen.

Schlüsselwörter: Schulentfremdung, Autonomie- und Kompetenzunterstützung, Soziale Eingebundenheit, (Un-)Gerechtigkeitserfahrungen, Schüler_innenbedürfnisse

Secondary schools are generally considered to be less supportive of student needs than primary schools, with students who are often less motivated and more detached from learning (e.g., Symonds \& Hargreaves, 2016). There is a general consensus that many negative school phenomena evolve as students move from primary to secondary school (e.g., Stern, 2012). It has been shown that negative attitudes toward school arise over the course of students' educational trajectory, and particularly in secondary school, which can manifest into school alienation (e.g., Brown, Higgins, \&, Paulsen, 2003; Hascher \& Hagenauer, 2010). School alienation refers to the development of students detaching and withdrawing from school in various domains: School alienation can form towards a) the learning process, $b$ ) the teachers and c) their classmates (Ha- scher \& Hadjar, 2018). The focus in this paper is on a) alienation from learning $(\mathrm{AL})$.

Students alienated from the learning process at school experience a wide range of emotional and psychological difficulties (Johnson, 2005), which may result in behavioral disorders in school. From the perspective of schools, disciplinary problems and minimal student participation in class are some of the main issues (Demanet \& van Houtte, 2011; Hascher \& Hadjar, 2018; Johnson, 2005; Tarquin \& Cook-Cottone, 2008). Based on AL, students may also develop alienation from any form of institutionalized learning (i.e., academic alienation), which can eventually lead to their exclusion from "the community of learners in our learning society" (Hascher \& Hagenauer, 2010, p. 220). To prevent or to mitigate such detrimental consequences, we 
need to better understand AL and its relationship with factors related to the context it evolves in-that is, the school and classroom setting. So far, studies investigating AL in different educational settings (e.g., contrasting the settings of primary and secondary schools) are lacking (see also Hascher \& Hadjar, 2018).

In this article, we have investigated the relationships between proximal, non-cognitive variables and AL in two different school contexts. By investigating variables linked to the fulfillment of student needs and their association with AL in grade 4 (when students are not yet affected by any selection processes of the primary-to-secondary school transition) and in grade 7 (when transition effects should already have manifested themselves), we seek to deepen our understanding of school alienation from the learning process in both primary and secondary school.

\section{From Alienation toward School Alienation to Alienation from Learning}

The original concept of alienation can be traced back to Karl Marx's term "estranged labour" (1844), which denotes an unfavorable relationship between people and their work or the products thereof (Hascher \& Hadjar, 2018). In the school context, alienation has been described as "the estrangement of the learner from what they should be engaged in, namely the subject and process of study itself" (Mann, 2001, p. 8). Other studies have addressed the construct of alienation as a subcomponent of academic amotivation (Legault, Green-Demers, \& Pelletier, 2006), as the opposite of engagement (Case, 2008; Glanville \& Wildhagen, 2007), and as a mere synonym for disengagement (Altenbaugh, Engel, \& Martin, 1995). It has also been suggested, however, that alienation is not a prerequisite for disengagement (Barnhardt \& Ginns, 2014). Until recently, we lacked a clear definition of what lies at the core of school alienation, and a profound discourse on how it differs from other similar constructs and how it should be measured was missing. A recent study reviewed the corpus of alienation literature, considering the plethora of definitions, conceptualizations, and operationalizations of school alienation (Hascher \& Hadjar, 2018). Based on theoretical and empirical findings, the authors addressed school alienation as a multidimensional and domain-specific construct.

In our study, we follow Hascher and Hadjar's (2018) conceptualization of school alienation as consisting of negative attitudes that develop in a domain-specific manner, encompassing both cognitive and affective components: Students can be alienated (a) from learning processes at school and/or (b) from social actors at school (i.e., their classmates as their peer community (c) and/or their teachers as part of the social environment and representa- tives of the school community. The cognitive component refers to students' perceptions, assumptions, and beliefs in relation to learning, classmates, and teachers, while the affective component is related to students' feelings toward these three domains of schooling. As shown by the validation study on the School Alienation Scale (Morinaj et al., 2017), emotion and cognition can be viewed as interrelated psychological processes, given relatively high positive correlations between emotional and cognitive aspects. The same study showed that the school alienation domains can be considered as relatively independent but interrelated dimensions. Additionally, the degree of alienation may differ depending on the domain measured-that is, students may be more alienated from one domain, e.g., from their teachers, for instance, than from another domain, e.g. from their peers (e.g., Brown et al., 2003). We assume that not only the degree but also the underlying causes and the ensuing consequences vary across the different domains. In the current study, the focus lies on the learning domain of school alienation, i.e., alienation from learning.

Alienation from learning (AL), as one of three domains of school alienation, refers to students' negative perception of the learning environment, the learning tasks and the learning process, cumulating in students' complete withdrawal from learning in school. AL has been differentiated into a process "characterized by discrepancies that a student perceives between his or her preferred vs. actual experience as a learner, or between a student's own activity vs. affect (selfestrangement) as a learner" (Barnhardt \& Ginns, 2014, p.973), while an alienated state is "a sense of disconnection between one's self and the task of meaningful learning, and / or between one's own activity and affect (self-estrangement) in relation to the task of meaningful learning" (Barnhardt \& Ginns 2014, p.973). AL can thus change in terms of a state and ultimately solidify in terms of a trait (see also Hascher \& Hadjar, 2018). We have followed Hascher and Hadjar (2018) and conceptualized AL as a set of negative attitudes towards learning at school, while alienated behaviors (e.g., low student participation, deviancy) or alienated forms of learning motivation are considered to be causes and / or consequences of this phenomenon.

Students alienated from learning struggle to find any relationship between the school's curriculum and their social realties outside the educational institution (Çağlar, 2013). In this regard, AL shows similarities to the utility value construct (as conceptualized in expectancy-value theory), which refers to how well a certain learning task fits with students' future plans and how useful for future endeavors they believe it to be (Wigfield \& Eccles, 2000). In line with previous findings on the development of school alienation, children's subjective values of school tasks tend to decline as they go through school, and to be most vulnerable to declines after school transitions and structural 
changes in the school environment (Watt, 2004). However, the declines in utility values were found to vary across different school subjects (e.g., Wigfield et al., 1997).

Although a few studies have recently theoretically outlined AL as a generalized negative orientation toward learning in school (see also Hascher \& Hadjar 2018; Morinaj et al., 2017), or in other words, a more general negative attitudinal phenomenon across different subjects in a school syllabus, this topic requires further investigation. AL at school may contribute to the growth of negative attitudes toward education in general and result in an even broader sense of academic alienation (i. e., students becoming alienated from various kinds of institutionalized learning).

\section{Toward a Conceptualization of Student Needs}

An array of needs-related theories (e.g., Alderfer, 1972; Maslow, 1943; McClelland, 1961; Murray, 1938) has constituted the theoretical basis for past and current empirical psychological studies. The needs concept is often positively connoted as a nutriment; a human being is said to require the fulfillment of both physiological and psychological needs for their optimal growth, health, and wellbeing (Ryan \& Deci, 2017). In other approaches the term "need" is negatively associated with deprivation, lack, harm or discrepancy and needs to be avoided, or it is used as a place-holder for goals, drives, and potential which cannot be categorized as either positive or negative such as in Maslow's hierarchical sets of goals, drives or motivators of human behavior (Watkins \& Kavale, 2014).

According to Ryan and Deci (2017), the concept of human psychological needs has often been conflated with other motivational concepts such as wants, motives, desires, or preferences-all of which represent motivating forces in people; however, to be called a basic psychological need, its satisfaction must foster well-being, and its deprivation significantly cause harm in the individual, which is not necessarily the case for mere wants or desires. To be a student need, its fulfillment must, thus, lead to observable, positive consequences for students' learning outcomes and well-being in school, or its nonfulfillment must cause significant harm.

Most needs theories in psychology (e.g., Maslow's Hierarchy of needs or Deci and Ryan's Basic Psychological Needs Theory) focus on individual-level needs; nevertheless, there are also group-specific needs, and the definition of needs, thus, must be placed within its context, ranging from micro- to meso-level (e.g., social groups, organizations, institutions, but also entire societies may have their own set of needs) (Kaufman, 2011; Watkins \& Kavale, 2014). Consequently, a school constitutes one particular context and the students of a school form a particular group with their own particular needs."

\section{The Role of the School Context and Student Needs in AL}

\section{School Context and AL}

AL may begin in the early grades (Finn, 1989), but increases in particular during adolescence, and is aggravated by the educational transition from primary to secondary school (Hascher \& Hadjar, 2018). Following initial curiosity and high expectations along with positive feelings and thoughts about the new secondary school (Booth \& Gerard, 2014), a downward spiral seems to set in (Wang \& Eccles, 2012). This phase is associated with students' loss of enjoyment of learning and engagement at school, which is often accompanied by a decline in their achievement within the new educational setting and thus has become an issue of great international educational concern (e.g., McGee, Ward, Gibbons, \& Harlow, 2003; OECD, 2004, 2017).

Explanations for this decrease in students' interest and the emergence of more negative orientations in secondary school may be drawn from the stage-environment fit theory (SEF; Eccles \& Midgley, 1989). According to SEF theory, negative changes in young adolescent students' lives do not merely result from maturational processes but also partly from an increasing misfit between the adolescents' educational environment and their developmental needs. Such students are in a developmental stage, growing from children into adolescents, but very often schools do not respond to the associated changes. The resulting misfit can lead to a decline in mental wellbeing and school engagement, triggering feelings of estrangement which, in turn, may result in a drop in the affected students' performance (Eccles \& Midgley, 1989).

As students enter secondary education, they face substantial changes in their school environment. Primary school environments are typically smaller, with classroom teacher systems and stable peer groups, whereas the new secondary schools more often are bigger and characterized by a less familiar atmosphere (Eccles \& Midgley, 1989). In addition, ability grouping or tracking not only makes school days more demanding for most secondary students, but also results in diverse organizational structures and classroom practices that vary considerably from school to school (Eccles \& Midgley, 1989). Students may experience their new secondary school settings quite differently depending on how the schools and their teachers in particular assist them in adapting to the new school environment (Hagenauer, Reitbauer, \& Hascher, 2013) and support them in fulfilling their needs. While some research has concluded that students' perceptions of school with regard to need fulfillment indeed change for the worse when students enter secondary school (e.g., Barber, \& Olsen, 2004), another study could not find proof that there was an abrupt change in students' perception of needs support associated 
with the transition phase, but rather an age-related linear downwards trend throughout students' school trajectories (e.g., Bru, Stornes, Munthe, \& Thuen, 2010).

\section{Student Needs and AL}

The satisfaction of the basic psychological needs for competence, autonomy, and relatedness, as defined in self-determination theory (SDT), has been identified as an important predictor for individuals' wellbeing, the development of intrinsic motivation, integrity, and growth (Deci \& Ryan, 2000). If students' needs are not satisfied in educational settings, intrinsic motivation will be undermined, leading to a so-called "'alienated' type of extrinsic motivation that is associated with low student persistence, interest, and involvement" (Ryan \& Deci, 2000, p.56). Alienation may ensue from indifferent, unstable motivational dispositions combined with situationally demotivating school experiences (Legault et al., 2006). Hence, from the perspective of SDT, the development of AL can be explained as the severe outcome of educational settings that hinder or do not allow students to fulfill their basic psychological needs (Ryan \& Deci, 2000). When the basic needs are not met, reduced motivation or alienated extrinsic motivation can follow, ultimately causing an overall sense of alienation and anomie (Deci \& Ryan, 2000).

Studies have shown that alienation in a school setting can arise from recurrent negative school experiences and low achievement (Eccles \& Roeser, 2009; Hascher \& Hagenauer, 2010; Tarquin \& Cook-Cottone, 2008). Low achievers have been found to be particularly at risk for school alienation (Hascher \& Hagenauer, 2010) and to generally experience less competence in their daily school lives. Students are accustomed to referring to their school grades in the construction of competence views about their own academic abilities (Gniewosz, Eccles, \& Noack, 2012). Hence, if students repeatedly receive negative feedback in the form of low grades, it can affect their self-efficacy beliefs, consequently causing students to withdraw from the learning process (Eccles et al., 1993; Legault et al., 2006).

Although the secondary school learning environments vary as to how well students are provided with the optimal structure and feedback necessary for them to experience competence (Wang \& Eccles, 2012), students seem generally to experience less competence in secondary than in primary school due to higher academic demands in the new school setting (Alspaugh, 1998; McGee et al., 2003). Moreover, in secondary school, students are allocated to different school tracks based on prior academic achievement in primary school. Those students that have not been assigned to the desired educational program might move to their new schools already with a sense of school failure. Together with low school grades, achievement tracking may be another factor in students' school experiences trig- gering the development of alienation in secondary school (Reilly \& Mitchell, 2010).

In addition, students may perceive the decision-making process regarding their allocation to a particular school track as externally determined and, as a result, their basic need for autonomy - naturally desired by maturing adolescent students (Eccles et al., 1993) - may be particularly thwarted in secondary school. Secondary schools are also said to be generally more controlling than primary schools, possibly due to prevailing stereotypes about early adolescents (Midgley, Feldhaufer, \& Eccles, 1988) and because the subject teacher system and larger classes in most secondary schools make it harder for the teachers to get to know and trust the students than it is for their colleagues in primary school.

At the same time, young adolescents are confronted with the task of finding a balance between wanting to belong to a peer group and being rejected or isolated from a social group; according to Newman and Newman (2003), this makes early adolescence (i.e., ages 13-17) a phase of particular vulnerability to alienation. Deci and Ryan (2000) further contend that a sense of relatedness is a necessary precondition for students to cherish certain classroom values that are important for student motivation, learning, and goal pursuit. If students are deprived of this function of the school (i.e., not able to share their values, beliefs, and fears with peers), and if they cannot fulfill their need for relatedness, alienation may ensue, impacting students' attitudes toward all aspects of schooling. Students who feel disconnected from their classmates tend to be less motivated to study and perform well at school (e.g., Skues, Cunningham, \& Pokharel, 2005). In the same vein, teachers perceived by the students as neglectful, disrespectful, unfair, and unmotivated have been found to reinforce student feelings of alienation from school and the learning process (Dalbert, 2011; Hascher \& Hagenauer, 2010; Murdock, 1999; Osterman, 2000). Accordingly, prior empirical research has shown that the student-teacher relationship and peer integration have a particularly powerful impact on school alienation (Hascher \& Hagenauer, 2010).

\section{Teacher (In-)justice and AL}

Early on, nonsatisfaction of student needs and injustice perceptions were considered key factors in the process of alienation (Finn, 1989). Similar to nonsatisfaction of basic needs, perceptions of injustice can negatively affect students' wellbeing, motivation, attitudes toward, and actual behavior at school (Hascher, 2004; Resh \& Sabbagh, 2014), whilst perceptions of basic needs support and justice can both foster engagement (Tyler \& Blader, 2003).

Justice and its effects on individuals' behavior and development in a social context have been fairly well re- 
searched in organizational psychology (e.g., Colquitt, Greenberg, \& Zapata-Phelan, 2005). Only recently has justice, as a factor in students' wellbeing, engagement, and ultimately learning, received more attention in the educational sciences (e.g., Dalbert, 2013). Nevertheless, a sound theory which incorporates justice is still lacking and empirical investigations into the potential impacts of perceptions of (in-)justice on student learning, motivation or attitudes are scarce. Despite referring to justice several times in the development of his theory of human needs and motivation, Maslow (1943) did not declare it to be a basic human need. Recent research, however, has suggested giving this neglected factor its due status as a basic psychological human need (Taylor, 2017). Whether and how justice is linked to the three psychological basic needs-autonomy, competence, and relatedness-is yet to be determined. Research in occupational psychology has shown that justice plays a key functional role in regulating autonomy satisfaction during decision-making procedures (van Prooijen, 2009). Autonomy dissatisfaction may go hand in hand with students feeling treated unfairly. In other words, students may feel unfairly treated if they think they are not given a voice during any decision-making processes at school or lack autonomy in their daily school lives.

In recent empirical studies, students' perceptions of fairness have been found to be highly correlated with students' expressions of alienation (Çağlar, 2013; Dalbert, 2011; Mahmoudi, Brown, Saribagloo, \& Dadashzadeh, 2015; Pretsch et al., 2016). Teachers play a crucial role in this relationship, as they are primarily in charge of providing rewards, individual learning opportunities, feedback, evaluations, and needs support in the classroom and, thus, can be viewed as the main sources of (in-)justice in the school context (Resh \& Sabbagh, 2014). Relatedness in the classroom is associated with students feeling that their teachers genuinely like, value, and respect them (Niemiec \& Ryan, 2009). A positive teacher-student relationship, characterized by mutual respect and recognition, cannot be established when students perceive that teachers treat them unfairly. Thus, perceived teacher injustice can also be viewed as an indicator of students' perception of the teacher-student relationship, which has been found to be a substantial factor in students' feelings of overall integration in the classroom and ultimately their sense of belongingness in the entire school environment (e.g., Donat, Umlauft, Dalbert, \& Kamble, 2012; Jiang, Liu, Ding, Zhen, Sun, \& Fu, 2018), or the lack thereof (Hascher \& Hagenauer, 2010). Therefore, students' perception of teacher injustice is considered to be an indicator of a lack of teacherstudent relatedness.

Similar to the universality of the three basic psychological needs (Deci \& Ryan, 2000), justice in general seems to be a matter of significance for all human beings at any stage in their life (Taylor, 2017). But the little empirical evidence on justice in an educational context implies that there are vast individual differences in perceptions of justice and that these vary across school contexts and student age cohorts (Peter, Donat, Umlauft, \& Dalbert, 2013). The period of adolescence is characterized by changes in social behavior: social interactions become more prosocial and less competitive (Eisenberg, Miller, Shell, McNalley, \& Shea, 1991; Steinberg, 2005). Students' prosocial behavior and concerns grow with the increasing ability to adopt perspectives other than their own (Eisenberg et al., 1991; Martin, Sokol, \& Elfers, 2008). Consequently, as students enter adolescence and at the same time move to secondary school, they may become more sensitive to issues of fairness or justice in the classroom as compared to when they were still at primary school. Indeed, empirical studies have shown such age-related changes in awareness and concerns about fairness issues (Güroğlu, van den Bos, \& Crone, 2009).

Accordingly, increased AL in secondary school, accompanied by a lack of interest in and enjoyment of school, as well as a lack of learning and achievement motivation, can be viewed as the consequence of educational settings that do not allow students to fulfill their basic psychological needs (i.e., their need to experience competence, autonomy, and relatedness), and fail to prevent or foster perceptions of injustice.

\section{Aim of Research and Hypotheses}

The aim of the study was twofold. First, we aimed at exploring whether grade 4 and grade 7 students significantly differed in AL, with higher levels in secondary school (Hypothesis 1). We expected grade 7 students to exhibit higher AL due to the onset of early adolescence and students' move to secondary schools that often fail to meet students' needs (Eccles \& Midgley, 1989). Secondly, we aimed at investigating the association between student needs fulfillment (as reflected by teacher competence and autonomy support, peer integration, and teacher injustice perceptions) and AL. Previous findings have shown that students' attitudes toward school and students' perceptions of needs support in the learning environments are correlated (e.g., Çağlar, 2013; Mahmoudi et al., 2015). The current study went beyond prior research by examining the quality of the associations between the aforementioned constructs and AL in two different school contexts (i.e., primary and secondary school).

Based on the theoretical considerations and previous empirical findings presented earlier, we proposed that competence support, autonomy support, and peer integra- 
tion were negatively associated with AL (Hypotheses 2a2c), whereas teacher injustice (as an indicator for a lack of teacher-student relatedness) was positively associated with AL (Hypothesis 2d). Because students are used to referring to their school grades in the construction of competence views about their academic abilities, we controlled their mean school grades. We further controlled students' gender, as boys have been found to be more strongly alienated than girls (Hadjar \& Lupatsch, 2010; Hascher \& Hagenauer, 2010). We assume that the proposed associations can be found for both school contexts (Hypothesis 3), because these needs are theorized to be universal in nature and need to be fulfilled and supported for students among all age groups in order for them to become fully engaged at school (Deci \& Ryan, 2000; Taylor, 2017). However, due to differences in the school contexts, and because adolescent secondary school students are more concerned with and increasingly aware of their own needs and their teachers' role in supporting needs fulfillment than primary school student (e.g., Eccles \& Midgley, 1989), these needs may be perceived as supported and fulfilled to a different level across the different school contexts. Hence, we expect to find lower mean scores for all needs-related variables in secondary rather than in primary school (Hypothesis 4).

\section{Method}

\section{Participants and Sampling}

The sample included 486 students from Swiss primary schools in grade $4\left(M_{\text {age }}=10.36\right.$ years $[S D=.98] ; 47.3 \%$ male) and 550 secondary school in grade $7\left(M_{\text {age }}=13.00\right.$ years $[S D=.55] ; 45.2 \%$ male). Data was collected within the framework of the binational research project "School Alienation in Switzerland and Luxembourg" (SASAL) using a standardized paper-and-pencil questionnaire, personally administered by trained personnel during normal school hours at the beginning of the second school semester in the Swiss canton of Bern in 2016. Within this project, a priori power analyses were conducted to determine the minimum sample size to test complex models, using the power analysis program for statistical tests $G^{*}$ Power (Faul et al. 2007). The analyses were based on the amount of error we were willing to tolerate (i.e., $+/-5 \%$ ) and indicated that 400 subjects per group were needed in order to detect small effects with reasonable power when employing the .05 criterion of statistical significance.

Schools, teachers, and students were solicited by convenience sampling. Random sampling of schools and classes was considered impossible, because the Bernese schools have been subject to many empirical studies and interventions in recent years. Nevertheless, a great effort was made to include a range of urban, suburban, and rural schools in order to generate a well-balanced sample. In a first step, school principals and class teachers were approached and given information about the goals and benefits of the research project. In a second step, class teachers asked their students to participate and distributed consent forms to be signed by parents. Students were assured of anonymity and confidentiality as well as given incentives to increase participation. In total 31 primary and 30 secondary school classes from 40 schools participated in the study with a participation rate of $85 \%$ to $100 \%$ of students per class.

The Swiss education system is quite diverse, because the responsibility for education mainly lies with the 26 cantons and the local municipalities that run the schools (EDK, 2017), leading to inter-cantonal and local differences. Children enter primary school in most cantons when they are about six years old and, depending on the canton / municipality, stay in primary school until grade 4,5 , or 6 (EDK, 2017).

In lower secondary education, students are taught in ability groups for all or some subjects and are allocated to different school tracks. In the canton of Bern, the Real (the lower) track usually leads to vocational training, whereas the Sek (the middle) and the Spez-Sek (the upper) tracks may conclude in academic training at grammar schools (Kantonsschule or Gymnasium), which prepare students for further studies at the university level, the Spez-Sek track being the most direct path. In 2015/16, 35\% of Bernese students were in the Real track, $60 \%$ in the Sek or Spez-Sek tracks, and the remaining $5 \%$ in private schools or classes with special-needs support (Allraum, Marti, Wassmer, \& Bucher, 2016). The majority of the secondary students in our sample (64\%) were students from the Sek and Spez-Sek tracks, while the remaining $36 \%$ attended the Real track, approximating the distribution in the population in the Swiss canton of Bern.

\section{Measures}

The dependent variable, AL, is one of three subscales of the newly developed School Alienation Scale (SALS) (Hascher \& Hadjar, 2018; Morinaj et al., 2017). A validation study has provided empirical support for a three-factor structure of school alienation (i.e., alienation from learning, alienation from teachers, and alienation from classmates), and the SALS was found to be a reliable measure of school alienation in all three domains (Morinaj et al., 2017). AL is defined as a specific set of negative attitudes toward learning in a school setting, including both emotional and cognitive elements. This measure was derived from students' responses to statements describing their learning experiences. AL scores were derived from eight items (e.g., "Learning at school is a com- 
plete waste of time" (cognitive aspect); "I don't find pleasure in learning at school" (emotional aspect); $\alpha=.87$ and $\omega=.87$ for grade 4 , and $\alpha=.88$ and $\omega=.88$ for grade 7 ). The following explanatory variables were included.

The competence support and autonomy support scales were adapted from Müller and Thomas (2011). Each scale was composed of five items measuring students' perceptions of how well their teachers support them in gaining a sense of mastery over learning content (e.g., "My teachers explain the learning content really well" for the competence support scale) and how well they understand their perspectives and encourage them in expressing their own thoughts (e.g., "My teachers are responsive to our suggestions and ideas" for the autonomy support scale). Internal consistency reliability of both scales ranged between $\alpha=.78$ and $\omega=.79$, and $\alpha=.83$ and $\omega=.83$ for both grade 4 and grade 7 .

The peer integration scale consisted of seven items adapted from Rauer and Schuck's (2003) questionnaire on emotional and social experiences at school (FEESS 3-4). Including items such as "My classmates are kind to me", it captures the extent to which students feel accepted and supported by their classmates. High scores on this scale, thus, indicate a strong sense of relatedness in class. Internal consistency reliability was good, with $\alpha=.89$ and $\omega=$ .89 for grade 4 , and $\alpha=.88$ and $\omega=.89$ for grade 7 .

The scale teacher injustice comprised four items, adapted from Dalbert und Stöber's (2002) Just School Climate scale. It measured students' feelings of unfairness at school, at the hands of teachers (e.g., "My teachers do not treat me fairly"; $\alpha=.70$ and $\omega=.73$ for grade 4 , and $\alpha=.74$ and $\omega=.74$ for grade 7 ).

For each item, participants rated their agreement on a four-point Likert scale ranging from 1 (not true) to 4 (true). Factor analyses have proven adequate construct validity of all measures in both groups (i.e., grade 4 and grade 7). Included in the analysis were the covariates: gender (female $=0$, male $=1$ ) and mean school grades as one indicator of academic achievement. The mean scores reflecting students' current school performance were based on their final grades in German, French, and mathematics (the main subjects in Swiss schools) at the end of the second semester, as provided by their teachers. In Switzerland, a sixpoint grading scale is used, where 6 represents the highest and 1 the lowest possible grade.

\section{Analytic Strategy}

The present study aimed at examining relationships across two different school contexts, i.e., primary and secondary school. By applying structural equation modeling (SEM) using a multigroup approach, the relationships between the dependent variable AL and the independent variables were analyzed at the student level within each school context. Moreover, it was investigated whether the relationships between AL and the independent variables are similar across the two subsamples. Lastly, we compared the latent mean scores of all factors across the two groups-given scalar invariance.

Before performing SEM, the frequency distributions of AL were checked for normality and the missing data patterns were evaluated. The percentage of missing values due to student nonresponse varied between $0.4 \%$ and $32.7 \%$ (i.e., autonomy support being the variable with the highest amount of missing values followed by competence support with $29.8 \%$ ) in grade 4 and $0.2 \%$ and $5.5 \%$ in grade 7 at the item level.

The full information maximum likelihood (FIML) estimation was used as a means for handling the missing data. It produces accurate standard errors by retaining the sample size (Schlomer, Bauman, \& Card, 2010). With FIML, parameters are estimated based on the available complete data and the implied values of the missing data (Enders, 2006). The distribution of AL as assessed by the ShapiroWilk' s test $(p<.05)$ and inspection of Q-Q plots deviated from normality in both samples; hence we applied an estimator with robust standard errors (i.e., robust maximum likelihood estimation method) to obtain reliable statistical results (Brown, 2015).

In order to identify the most appropriate statistical technique for the main analytic procedure, we explored to what extent AL and the independent factors were individually experienced and/or classroom phenomena. Although there was a significant amount of variance between classrooms, the intraclass correlation coefficient (ICC) for AL indicated that most of the variance in AL can be attributed to withinclassroom differences (i.e., $89 \%$ in grade 4 and $87 \%$ in grade 7). The same applies to the independent factors, with ICCs ranging between .01 and .10, indicating that $90-99 \%$ of the variation in the independent factors is to be attributed to individual differences (see Table 1). Based on this considerable amount of variability at the student level and because the focus of this study is on students' individual and subjective perceptions of their situation in the classroom, SEM seemed to be an appropriate method of analysis. Stratification, non-independence of observations, and unequal probability of selection due to data from students nested in classrooms were taken into account and the standard errors and chi-squared test of model fit were adjusted accordingly (command type is complex) (Muthén \& Muthén,1998-2012).

The main analyses contained two major steps. We first conducted measurement invariance (MI) tests, as MI is a prerequisite for valid group comparison (e.g., Millsap, 2012). We applied multigroup confirmatory factor analysis (CFA), a well-recognized approach for testing MI across particular groups of interest (Steenkamp \& Baumgartner, 
1998). A step-up procedure was employed, following Christ and Schlütter (2017): First, separate measurement models for $\mathrm{AL}$ and the independent factors for each group were constructed to test for configural invariance (to test whether the same CFAs were valid for both grade 4 and grade 7). None of the parameters were constrained to be equal across the groups in the configural models, and their fit indices served as baseline values for all subsequent models in testing for MI. Second, factor loadings were held equal across groups, but the intercepts were allowed to differ to test for metric invariance. As metric invariance, or at least partial metric invariance-a prerequisite for further MI testing (Vandenberg \& Lance, 2000)-was confirmed, scalar invariance or partial scalar invariance, respectively, was tested by keeping the earlier specified constraints in addition to constraining item intercepts to be the same across groups. Lastly, we conducted Satorra-Bentler scaled difference chisquared tests between the non-restricted and restricted models (Satorra \& Bentler, 2001). A non-significant result of the chi-square difference test would indicate invariance between the models. In addition, following the guidelines for testing measurement invariance with an adequate sample size (i.e., total $N>300$; Chen, 2007), for testing metric and scalar invariance, a change of $\geq-.010$ in CFI indicate noninvariance. The difference in CFI $(\triangle \mathrm{CFI})$ was chosen as the main criterion to define invariance, representing the empirically best supported criterion for determining evidence of measurement invariance (Chen, 2007; Cheung \& Rensvold, 2002; Hirschfeld \& von Brachel, 2014).

In the next step, we addressed our hypotheses regarding the relations between students' gender, achievement, perceived competence and autonomy support, teacher injustice, peer integration, and $\mathrm{AL}$, using multigroup SEM. To test whether some of the structural path coefficients differed significantly for primary and secondary school stu- dents, we ran two models, one with the paths held equal and a second one with the paths not constrained to be equal. A chi-squared difference test of the unstandardized coefficients was subsequently run to determine whether the associations between the investigated variables were significantly different across primary and secondary schools. For both MI and SEM analyses, we assessed the goodness of fit of our statistical models based on several fit indices: Chi-square, the Comparative Fit Index (CFI), the Root Mean Square Error of Approximation (RMSEA), and the Standardized Root Mean Square Residual (SRMR). RMSEA and SRMR values of close to 0.05 or less indicate a close fit of the model in relation to the degrees of freedom (Hu \& Bentler, 1999; Schermelleh-Engel, Moosbrugger, \& Müller, 2003) and CFI values close to 1 a very good fit (Browne \& Cudeck, 1993; Schermelleh-Engel et al., 2003).

Finally, based on the results of the MI analyses, we further conducted the test of factor mean differences between the groups. We compared the model in which the factor means were fixed to zero in both groups to the model in which the factor means were fixed to zero only in one group (Muthén \& Muthén, 1998-2012). The fit of the two models was then compared using chi-square difference testing (Satorra \& Bentler, 2001).

\section{Results}

\section{Sample Description}

The descriptive statistics and intercorrelations of the variables for grade 4 and grade 7 are shown in Table 1. Significant relationships were found between $\mathrm{AL}$ and all independent

Table 1. Descriptive Statistics and Intercorrelations of the Study's Variables

\begin{tabular}{|c|c|c|c|c|c|c|c|c|c|}
\hline & Grade 4 & Grade 7 & & & & & & & \\
\hline Variable & $M(S D)$ & $M(S D)$ & 1 & 2 & 3 & 4 & 5 & 6 & 7 \\
\hline 1. Male (female) & $.47(.50)$ & $.45(.50)$ & & $-.20 * \star$ & -.01 & -.05 & $-.11 *$ & $.24^{* *}$ & $.11 * *$ \\
\hline 2. Mean school grades ${ }^{a}$ & $5.04(.55)$ & $4.73(.46)$ & $-.16 * \star$ & & $.09 *$ & .07 & $.12^{\star \star}$ & $-.25^{\star \star}$ & $-.13 * \star$ \\
\hline 3. Competence support b & $3.58(.48)$ & $3.33(.50)$ & -.03 & $.13^{*}$ & & $.61 * \star$ & $.28 * \star$ & $-.39 * *$ & -.45 \\
\hline 4. Autonomy support ${ }^{b}$ & $3.43(.51)$ & $3.23(.52)$ & -.05 & .05 & $.58 * *$ & & $.24 * \star$ & $-.40 * \star$ & $-.42^{\star \star}$ \\
\hline 5. Peer integration ${ }^{b}$ & $3.43(.60)$ & $3.42(.58)$ & .01 & .09 & $.20 * \star$ & $.28 * \star$ & & $-.27 * \star$ & $-.15^{\star *}$ \\
\hline 6. Teacher injustice ${ }^{b}$ & $1.50(.57)$ & $1.50(.53)$ & .04 & $-.25^{\star \star}$ & $-.35^{\star \star}$ & $-.37 * \star$ & $-.27 \star \star$ & & $.42 * \star$ \\
\hline 7. Alienation from learning ${ }^{b}$ & $1.54(.53)$ & $1.83(.56)$ & $.11^{*}$ & -.05 & $-.34 * \star$ & $-.32 * \star$ & $-.20 * \star$ & $.32 * \star$ & \\
\hline \multicolumn{5}{|c|}{ Intraclass correlation coefficient grade 4} & .10 & .04 & .03 & .05 & .11 \\
\hline \multicolumn{5}{|c|}{ Intraclass correlation coefficient grade 7} & .14 & .09 & .09 & .10 & .13 \\
\hline
\end{tabular}

Notes: Grade 4 correlations are below the diagonal $(N=486)$; grade 7 correlations are above the diagonal $(N=550) ;{ }^{*} p<.05,{ }^{* *} p<.01 .{ }^{a}$ Variable coding:

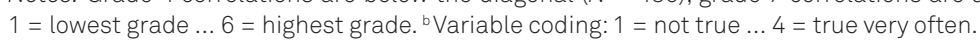


variables in both grades. The patterns of correlation were as expected, also supporting the proposed direction of the association between basic needs support and AL.

\section{Measurement Invariance}

Measurement invariance was tested separately for all latent factors, applying the multigroup CFA method. All tests of measurement invariance were conducted via a series of hierarchically nested models (configural, metric, and scalar invariance models). The fit indices for the models that tested measurement invariance for AL are presented in Table 2. The model fit of the unconstrained configural model indicated that the same CFAs of AL are valid for both grade 4 and grade 7 (see Table 2). When testing for metric invariance, the chi-squared difference test (accompanied by testing for the difference in CFI $(\triangle \mathrm{CFI})$ between the baseline model and the metric invariance model indicated a significant decline in model fit. Hence, we proceeded to test for partial metric invariance. In this model, the factor loading of one item of the cognitive aspect of AL (i.e., AL_9 "What we learn at school, does not help me in life") was allowed to vary across the two groups. The chi-squared test was significant $\left(\chi^{2}=89.65, d f=37, p<.001\right)$, but as the chi-squared test is very sensitive to sample size and is not the sole indicator for acceptance or rejection (Browne \& Cudeck, 1993; Schermelleh-Engel et al., 2003), we assumed partial metric invariance based on a change of CFI $=.00$. An acceptable fit was also indicated by the overall fit indices CFI, RMSEA, and SRMR (see Table 2). Partial scalar invariance, however, could not be established as both indicated by the significant chi-squared test and the significant change of .03 in CFI.

The test of measurement invariance was also conducted separately for the independent variables, including autonomy and competence support, teacher injustice, and peer integration, through a series of hierarchically nested models (configural, metric, and scalar invariance models). The fit indices for the models that tested measurement invariance are presented in Table 3. Each of the three invari- ance models produced an acceptable fit. The series of model comparisons in regard to autonomy and competence support indicated that metric and scalar invariance between primary and secondary school students was confirmed, indicating the equivalence of factor loadings and intercepts, because the chi-square test was not significant and $\Delta$ CFI was below .01 (Chen, 2007). In regard to injustice, the baseline model was just-identified with zero degrees of freedom. The model was compared to other nested models with zero degrees of freedom (zero was used for both chi-square and for the degrees of freedom). Model comparisons revealed that the factor loadings could be assumed to be equal (the chi-square test was not significant and $\triangle$ CFI was below .01). However, scalar invariance could not be established, revealing non-equivalence of intercepts between the two groups. After inspecting modification indices, potential sources for noninvariance were not detected. Testing measurement invariance of peer integration, the results indicated metric invariance across primary and secondary school students. However, neither scalar nor partial scalar invariance could be established.

Our findings, confirming scalar invariance for autonomy and competence support, metric invariance for injustice and peer integration, and partial metric invariance for AL between primary and secondary school students, suggest that differences in relationships between the two groups involving $\mathrm{AL}$ and student needs can be evaluated; however, this does not allow us to analyze mean differences for AL, injustice, and peer integration, as at least partial scalar invariance would be needed (e.g., Christ \& Schlütter, 2012). Although the average scores for AL imply higher levels of alienation in grade $7(M=1.83, S D=.56)$ than in grade $4(M=1.54, S D=$ $.54)$, we therefore had to refrain from testing Hypothesis 1 (i.e., grade 4 and grade 7 students significantly differ in AL, with higher levels of alienation in secondary school).

Hypothesis 4 (i.e., grade 7 students have higher mean scores across all independent factors than grade 4 students) could only partly be addressed: Based on the scalar invariance in regard to autonomy and competence support between primary and secondary students, we further conducted

Table 2. Measurement Invariance Tests across Primary and Secondary School Students for Alienation from Learning

\begin{tabular}{|c|c|c|c|c|c|c|c|c|c|}
\hline \multirow[t]{2}{*}{ Model } & \multicolumn{5}{|c|}{ Overall Fit Indices } & \multirow{2}{*}{$\begin{array}{c}\text { Model } \\
\text { Comparison }\end{array}$} & \multicolumn{3}{|c|}{ Comparative Fit Indices } \\
\hline & $\chi^{2}$ & $d f$ & $\mathrm{CFI}$ & RMSEA & SRMR & & $\Delta \chi^{2}$ & $\Delta d f$ & $\triangle \mathrm{CFI}$ \\
\hline \multicolumn{10}{|c|}{ Primary ( $n=453)$ and secondary $(n=497)$ school students } \\
\hline 1. Configural invariance & 94.50 & 30 & .98 & .06 & .04 & - & - & - & - \\
\hline 2. Metric invariance & 149.65 & 38 & .96 & .08 & .08 & 2 vs. 1 & $53.06 *$ & 8 & .01 \\
\hline 3. Partial metric invariance & 108.29 & 37 & .97 & .06 & .05 & 3 vs. 2 & $37.61^{\star}$ & 5 & .00 \\
\hline 4. Partial scalar invariance & 188.99 & 43 & .94 & .08 & .07 & 4 vs. 3 & $115.57 *$ & 6 & .03 \\
\hline
\end{tabular}

Notes: CFI = Comparative Fit Index; RMSEA = Root Mean Squared Error of Approximation; SRMR = Standardized Root Mean Square Residual; $\triangle$ = Difference between the comparison and nested model. $\triangle \mathrm{CFI} \geq-.010$ indicates noninvariance; ${ }^{\star} p<.001$. 
Table 3. Measurement Invariance Tests across Primary and Secondary School Students for Autonomy and Competence Support, Injustice, and Peer Integration

\begin{tabular}{|c|c|c|c|c|c|c|c|c|c|}
\hline \multirow[t]{2}{*}{ Model } & \multicolumn{5}{|c|}{ Overall Fit Indices } & \multirow{2}{*}{$\begin{array}{c}\text { Model } \\
\text { Comparison }\end{array}$} & \multicolumn{3}{|c|}{ Comparative Fit Indices } \\
\hline & $\chi^{2}$ & $d f$ & $\mathrm{CFI}$ & RMSEA & SRMR & & $\Delta \chi^{2}$ & $\Delta d f$ & $\Delta \mathrm{CFI}$ \\
\hline \multicolumn{10}{|l|}{ Autonomy Support } \\
\hline \multicolumn{10}{|c|}{ Primary $(n=329)$ and secondary $(n=539)$ school students } \\
\hline 1. Configural invariance & 9.12 & 8 & .99 & .02 & .02 & - & - & - & - \\
\hline 2. Metric invariance & 12.19 & 13 & .99 & .00 & .04 & 2 vs. 1 & 2.59 & 5 & .00 \\
\hline 3. Scalar invariance & 21.20 & 17 & .99 & .02 & .05 & 3 vs. 2 & 9.49 & 4 & .00 \\
\hline \multicolumn{10}{|l|}{ Competence Support } \\
\hline \multicolumn{10}{|c|}{ Primary $(n=341)$ and secondary $(n=540)$ school students } \\
\hline 1. Configural invariance & 40.37 & 10 & .97 & .07 & .03 & - & - & - & - \\
\hline 2. Metric invariance & 42.44 & 15 & .97 & .06 & .07 & 2 vs.1 & 4.07 & 5 & .00 \\
\hline 3. Scalar invariance & 49.88 & 19 & .97 & .06 & .08 & 3 vs. 2 & 7.21 & 4 & .00 \\
\hline \multicolumn{10}{|l|}{ Injustice } \\
\hline \multicolumn{10}{|c|}{ Primary $(n=452)$ and secondary $(n=543)$ school students } \\
\hline 1. Configural invariance ${ }^{a}$ & 0 & 0 & 1.00 & .00 & .00 & - & - & - & - \\
\hline 2. Metric invariance & 3.41 & 3 & .99 & .02 & .03 & 2 vs. 1 & 3.41 & 3 & .00 \\
\hline 3. Scalar invariance & 13.61 & 5 & .97 & .06 & .04 & 3 vs. 2 & $14.52^{\star}$ & 2 & .03 \\
\hline \multicolumn{10}{|l|}{ Peer Integration } \\
\hline \multicolumn{10}{|c|}{ Primary $(n=453)$ and secondary $(n=497)$ school students } \\
\hline 1. Configural invariance & 30.03 & 20 & .99 & .03 & .02 & - & - & - & - \\
\hline 2. Metric invariance & 46.41 & 27 & .99 & .04 & .07 & 2 vs.1 & 16.03 & 7 & .00 \\
\hline 3. Scalar invariance & 77.18 & 33 & .98 & .05 & .08 & 3 vs. 2 & $37.20^{*}$ & 6 & .01 \\
\hline
\end{tabular}

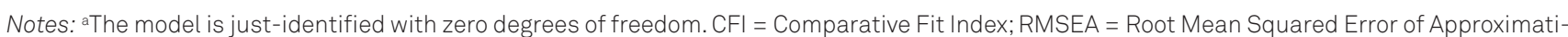
on; SRMR = Standardized Root Mean Square Residual; $\Delta=$ Difference between the comparison and nested model. $\Delta C F I \geq-.010$ indicates noninvariance. ${ }^{*} p<.001$.

the test of factor mean differences between the groups. The model in which the factor means were fixed to zero in both groups was compared to the model in which the factor means were fixed to zero in one group and set free in the other group (Muthén \& Muthén, 1998-2012). On the basis of chi-square difference testing between the models, the results revealed a significant mean difference across the groups in regard to both autonomy and competence support $\left(\Delta \chi^{2}=30.39, \Delta d f=1\right.$, $p<.01$ and $\Delta \chi^{2}=20.53, \Delta d f=1, p<.01$, respectively). Grade 7 students' average scores for autonomy and competence support $(M=3.23, S D=.52$ and $M=3.33, S D=.50$, respectively) are significantly lower than the grade 4 scores $(M=3.43, S D=$ .51 and $M=3.58, S D=.48$, respectively).

\section{Alienation from Learning, Basic Needs, and Teacher Injustice}

To analyze the relevance of variables related to student need fulfillment and teacher injustice for AL (Hypothe- ses 2-3), we used multigroup SEM, in which we also controlled gender and students' mean school grades as an indicator for their achievement at school. In a first step, a joint unconstrained model for both groups was estimated (i.e., coefficients were allowed to vary freely across grade 4 and grade 7). In the unconstrained model, the structural relationships were equally specified for both groups, but the coefficients in the relationships were estimated independently. Variances, error variances, and covariances of the latent variables were not constrained to be equal but freely estimated for each group. Factor loadings were held equal across groups. The resulting model fit the data well (see Table 4). The unconstrained models for both grade 4 and grade 7 are presented in Figure 1.

We found a significant negative association between students' perceived competence support from their teachers and AL in secondary school $(\beta=-.30, p<.05)$, partly confirming Hypothesis 2a. No significant association with autonomy support or peer integration was found; thus, Hypo- 


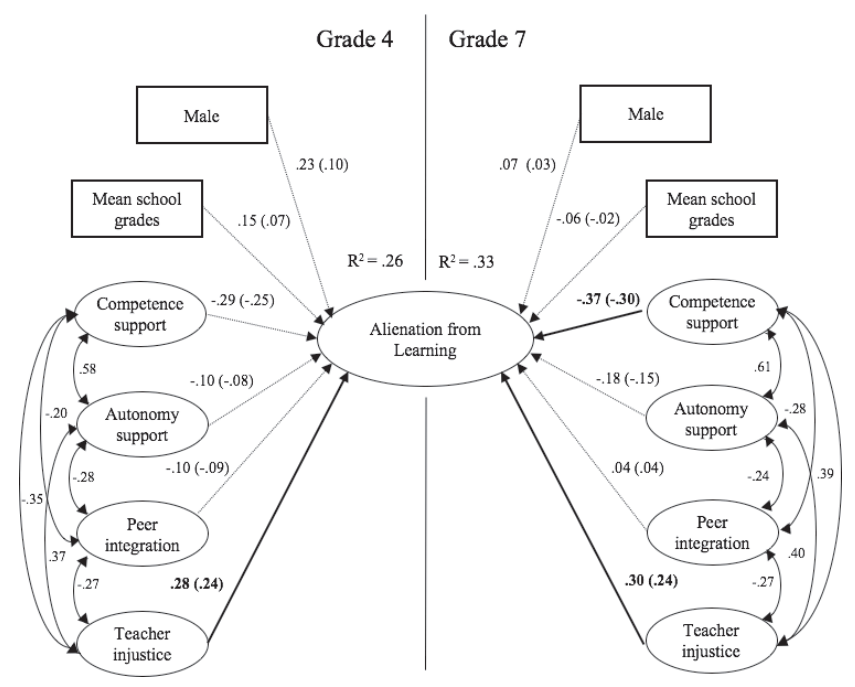

Figure 1. Unconstrained multigroup model of alienation from learning. Dashed lines represent non-significant relationships; $p>$.05. Standardized parameter estimates are presented next to the non-standardized estimates in brackets.

theses $2 b$ and $2 c$, respectively, are rejected. A significant positive relationship was found between perceptions of teacher injustice and AL in both primary $(\beta=-.24, p<.05)$ and secondary school $(\beta=-.24, p<.001)$, confirming Hypothesis $2 \mathrm{~d}$. The total variance accounted for in AL was approximately $26 \%$ in grade 4 and $33 \%$ in grade 7 . We found no significant gender or school grade effect.

In a second step, we estimated a joint constrained model in which the structural paths and factorial structure were constrained to be equal for both groups. A comparison of the goodness of fit statistics between the constrained and unconstrained model shows that the two models measured equally well (see Table 4), implying that the relationships between $\mathrm{AL}$ and the independent variables are similar for primary and secondary school.

In a last step, we compared the fit of the two models using the Satorra-Bentler scaled chi-square difference test. Because this test did not reveal significant differences between the constrained and unconstrained model $(p>.05$; see Table 4 ), and $\triangle$ CFI was explicitly below the recommended cutoff values, it can be concluded that the models did not differ significantly from each other (Hypothesis 3 is accepted). In other words, there are no significant differences in the associations between the independent variables and AL across grades 4 and 7, implying that the relationship structure between basic needs support and AL is similar across both primary and secondary school.

\section{Discussion}

The main purpose of this cross-sectional study was to examine the relationships between students' AL and their perceptions of teachers' and peers' basic needs support across primary and secondary school. This investigation has addressed a lack of studies in alienation research by focusing on non-cognitive variables related to the specific social context in which alienation evolves: that is, the classroom setting.

The current study initially aimed at exploring differences in AL across primary and secondary school contexts, assuming higher alienation in secondary rather than in primary school (Hypothesis 1). However, due to a lack of scalar measurement invariance, we could not test latent mean differences in AL across grade level. Although the mean scores indicated that grade 7 students exhibited slightly higher levels of AL than grade 4 students, further research is needed to investigate if AL is more salient in secondary than in primary schools. Moreover, longitudinal studies are necessary to prove that $\mathrm{AL}$ is in line with other negative developmental trends that indicate decreases in learning enjoyment (e.g., Hagenauer \& Hascher, 2014) and engagement (e.g., Symonds \& Hargreaves, 2016; Van Ophuysen, 2008) as students enter and proceed through secondary school.

In keeping with the assumption that AL may be related to a misfit between students' needs and their school environments (Eccles \& Midgley, 1989), we subsequently conducted multigroup SEM to investigate the relationships between basic needs support by teachers and peers and student AL in both primary and secondary school contexts. We found that perception of teacher injustice as an

Table 4. Global Goodness of Fit Comparison

\begin{tabular}{|c|c|c|c|c|c|c|c|c|c|}
\hline \multirow[t]{2}{*}{ Model } & \multicolumn{5}{|c|}{ Overall Fit Indices } & \multirow{2}{*}{$\begin{array}{c}\text { Model } \\
\text { Comparison }\end{array}$} & \multicolumn{3}{|c|}{ Comparative Fit Indices } \\
\hline & $\chi^{2}$ & $d f$ & $\mathrm{CFI}$ & RMSEA & SRMR & & $\Delta \chi^{2}$ & $\Delta d f$ & $\triangle \mathrm{CFI}$ \\
\hline \multicolumn{10}{|c|}{ Primary $(n=453)$ and secondary $(n=497)$ school students } \\
\hline 1. Unconstrained model & 1280.34 & 779 & .94 & .04 & .06 & - & - & - & - \\
\hline 2. Constrained model & 1283.63 & 785 & .94 & .04 & .06 & 2 vs. 1 & 4.79 & 6 & .00 \\
\hline
\end{tabular}

Notes: CFI = Comparative Fit Index; RMSEA = Root Mean Squared Error of Approximation; SRMR = Standardized Root Mean Square Residual; $\triangle=$ Difference between the comparison and nested model. $\triangle R M S E A$ and $\triangle$ SRMR were explicitly below the recommended cutoff values. 
indicator for a lack of student-teacher relatedness was significantly positively related to AL in both grade 4 and grade 7 (confirming Hypothesis 2d), whereas competence support was found to be negatively associated with $\mathrm{AL}$ only in grade 7 (partly confirming Hypothesis 2a). Neither in grade 4 nor in grade 7 was teacher autonomy support or peer relatedness significantly associated with AL. One possible explanation for the finding that a significant effect between teacher competence support and AL could only be found in grade 7 can be drawn from stage-environmentfit theory, positing that secondary students are generally less supported by their teachers in fulfilling their basic needs to experience competence in daily school life (e.g., Eccles et al., 1993). In addition, first-year secondary students, struggling with the demanding task of adjusting to their new school environment, tend to harbor more selfdoubt (Newman \& Newman, 2003). This finding supports our hypothesis that students who do not feel competent in school withdraw and distance themselves from the learning process. Although they may establish their competence in another domain (e.g., within their peer community) to protect their overall self-esteem and to sustain their basic self-confidence (e.g., Newman \& Newman, 2003), this development is harmful, as students need to experience competence in the learning domain in order to become actively engaged and motivated at school (Eccles \& Wang, 2012).

Despite the assumptions from various influential theories on motivation and adolescent development (e.g., Deci \& Ryan, 2000; Eccles et al., 1993; Reeve, 2012), our results did not reveal a significant negative effect between students' perceptions of their teachers' autonomy support and AL in either secondary or primary school. Our study focused on students that have only just entered both adolescence and secondary schooling. Autonomy may become more relevant as students mature and, thus, may only be of importance to students later on in in their secondary school trajectories. A study comparing further age cohorts could be beneficial in shedding more light on this complex relationship.

We further hypothesized that if the need for relatedness cannot be fulfilled, students' attitudes toward learning will be affected and AL could follow. Contrary to theoretical premises and previous empirical findings indicating that students will become more involved in learning activities at school if their need for relatedness to their classmates is met (e.g., Mahmoudi et al., 2015; Wang \& Eccles, 2012), we found that students' perception of peer relatedness was unrelated to AL in both primary and secondary schools. A possible explanation for this result could be that students draw on other sources to meet their need for relatedness, such as their teachers, parents, or peers outside of school (e.g., Malecki \& Demaray, 2003). This is partly supported by the next finding, which underpins the relevance of the student-teacher relationship for students' involvement in the learning process at school. We found a positive effect between students' perceptions of teacher injustice and AL in both grades, confirming our hypothesis and replicating earlier empirical findings (Çağlar, 2013). Injustice perceptions are of importance with regard to students' orientation toward learning at school; hence, future studies may want to investigate this neglected aspect more closely, for example by distinguishing different forms of (in-)justice (i.e., distributive, procedural, and interactional) and their individual effects on AL.

Based on the premises that AL may already be found in the earliest grades (Finn, 1989), and that the basic needs as well as the need for justice are universal in nature across different age spans (e.g., Taylor, 2017), we expected to find similar relationships across both groups (Hypothesis 3). Our results indicate no significant differences in the quality of the proposed associations between AL and the needsrelated variables (including injustice experiences) across grade level (i.e., Hypothesis 3 was accepted). This finding implies that the relational structure between basic needs support, injustice experiences, and AL is as previously asserted (e.g., Deci \& Ryan, 2000; Taylor, 2017) similar across the different developmental periods. The unanimous pattern of results across school grades further supports the assumption of domain-specificity of alienation (i.e., alienation from social and / or academic aspects of school) as has been theoretically outlined by Hascher and Hadjar (2018).

However, due to differences in school context and students' developmental stage, we expected lower scores in students' perception of need support in grade 7 than in grade 4 (Hypothesis 4 ). Hypothesis 4 could only partly be addressed due to scalar noninvariance for some of the variables. Perception of autonomy and competence support (for which scalar invariance was supported) significantly differed across the two student groups (Hypothesis 4 was partly accepted). Our results support those earlier empirical findings that have found students' perceptions of need support by teachers are worsening as students' progress in school and grow from children into adolescents (e.g., Barber \& Olsen, 2004).

The final SEM could explain a substantial amount of variance in AL (i.e., $26 \%$ and $33 \%$ for grade 4 and grade 7 , respectively). The remaining amount of unexplained variance indicates that other factors, possibly also outside the school setting, may play a crucial role in $\mathrm{AL}$, such as family support. As this was to the best of our knowledge the first study to explore potential non-cognitive determinants and precursors of AL, we exclusively focused on factors related to individual students' perceptions of basic needs support by teachers and peers. Being aware that AL is a multi-causal phenomenon and that factors related to this process 
might go far beyond the classroom, we suggest future studies apply a systemic approach, considering other individual, developmental, and environmental aspects, in addition to aspects beyond a school's institutional reach (e.g., students' socialization, their socio-economic and sociocultural backgrounds). Further limitations of this research lie in its cross-sectional design. It is impossible to infer causality and patterns of individual development regarding AL from the findings of this study. Hence, there is a need for both longitudinal studies that follow students throughout their school careers and over the primary-secondary school transition, and for studies combining quantitative and qualitative approaches. In the presence of scalar noninvariance in regard to particular variables, some hypotheses could not be addressed. Hence, there is a need for an improvement of the measurement instruments and testing of these scales across further contexts. Researchers could also consider mediation and moderation effects between the different basic needs.

Of particular significance in the current study is the finding that AL is primarily related to the teacher-student relationship (as shown by the significant effects between AL and competence support or teacher injustice), whereas peer relationships (as shown by the insignificant effects between AL and peer integration) seem to be of less importance both for primary and secondary school students. This lack of a significant association between peer support and AL further supports the assumption of domain-specificity of AL. In contrast, teacher injustice and a lack of student competence support correlates negatively with teachers' relationships with students and might ultimately negatively affect students' orientation toward the learning process at school. In this light, it seems important for teachers to establish a positive relationship with their students, characterized by competence support and mutual trust and fairness in the classroom through transparent evaluation practices and a respectful, appreciative, and supportive relationship with students. From a theoretical perspective, our findings imply that there is an effect between perception of teacher injustice and AL independently of and in addition to the effects of perceived competence and autonomy support. While teacher injustice can be regarded as an indicator for a lack of students' relatedness to their teachers, considering this factor could be viewed as a first step toward integrating the much-neglected construct of justice in research on basic needs and motivation.

\section{References}

Alderfer, C. P. (1972). Existence, relatedness, and growth: Human needs in organizational settings. New York, NY, US: Free Press.
Allraum, J., Marti, K., Wassmer, C., \& Bucher, M. (2016). Bildungsstatistik Kanton Bern: Basisdaten 2015. Bern: Abteilung Bildungsplanung und Evaluation, Erziehungsdirektion des Kanton Bern.

Alspaugh, J. (1998). Achievement loss associated with the transition to middle school and high school. Journal of Educational Research, 92(1), 20 - 25. https://doi.org/10.1080/00220679809597572

Altenbaugh, R. J., Engel, D. E., \& Martin, D. T. (1995). Caring for kids: A critical study of urban school leavers. London: The Falmer Press. https://doi.org/10.2307/369924

Barber, B. K., \& Olsen, J. A. (2004). Assessing the transitions to middle and high school. Journal of Adolescent Research, 19(1), 3-30. https://doi.org/10.1177/0743558403258113

Barnhardt, B., \& Ginns, P. (2014). An alienation-based framework for student experience in higher education: New interpretations of past observations in student learning theory. Higher Education, 68, 789-805. https://doi.org/10.1007/s10734-014-9744-y

Booth, M.Z., \& Gerard, J. M. (2014). Adolescents' stage-environment fit in middle and high school: The relationship between students' perceptions of their schools and themselves. Youth \& Society, 46(6), 735 - 755. https://doi.org/10.1177/0044118X12451276

Brown, T. A. (2015). Confirmatory factor analysis for applied research. New York, NY: Guilford Publications.

Browne, M. W., \& Cudeck, R. (1993). Alternative ways of assessing model fit. In K.A. Bollen \& J. S. Long (Eds.), Testing structural equation models (pp.136 - 162). Newbury Park, CA: Sage.

Bru, E., Stornes, T., Munthe, E., \& Thuen, E. (2010). Students' perceptions of teacher support across the transition from primary to secondary school. Scandinavian Journal of Educational Research, 54(6), 519 - 533. https://doi.org/10.1080/00313831.2 010.522842

Çağlar, C. (2013). The relationship between the perceptions of the fairness of the learning environment and the level of alienation. Eurasian Journal of Educational Research, 50, 185- 206.

Case, J. M. (2008). Alienation and engagement: Development of an alternative theoretical framework for understanding student learning. Higher Education, 55, 321-332. https://doi.org:10.1007/ s10734-007-9057-5

Chen, F. F. (2007). Sensitivity of goodness of fit indexes to lack of measurement invariance. Structural equation modeling, 14(3), 464-504. https://doi.org/10.1080/10705510701301834

Cheung, G. W., \& Rensvold, R. B. (2002). Evaluating goodness-offit indexes for testing measurement invariance. Structural equation modeling, 9(2), 233 - 255. https://doi.org/http://dx.doi. org/10.1207/S15328007SEM0902_5

Christ, O., \& Schlüter, E. (2012). Strukturgleichungsmodelle mit Mplus: Eine praktische Einführung. Munich, Germany: Oldenbourg Verlag.

Colquitt, J. A., Greenberg, J., \& Zapata-Phelan, C. P. (2005). What is organizational justice? A historical overview. In J. Greenberg \& J. A. Colquitt (Eds.), The handbook of organizational justice (pp. 3 - 56). Mahwah, NJ: Erlbaum.

Dalbert, C. (2011). Warum die durch die Schüler und Schülerinnen individuell und subjektiv erlebte Gerechtigkeit des Lehrerhandelns 1 wichtig ist. Zeitschrift Für Pädagogische Psychologie, 25(1), 81 - 82. https://doi.org/10.1024/1010-0652/a000033

Dalbert, C. (Ed.). (2013). Gerechtigkeit in der Schule. Wiesbaden: Springer-Verlag.

Dalbert, C., \& Stöber, J. (2002). Strukturierung und Autonomieunterstützung durch die Lehrerinnen. In J. Stöber, Skalendokumentation "Persönliche Ziele von SchülerInnen" (pp. 27 - 29). Halle (Saale), Germany: Martin-Luther-Universität Halle-Wittenberg.

Deci, E. L., \& Ryan, R. M. (2000). The "what" and "why" of goal pursuits: Human needs and the self-determination of behavior. Psychological Inquiry, 11(4), 227 - 286. https://doi.org/10.1207/ S15327965PLI1104_01 
Demanet, J., \& van Houtte, M. (2011). School belonging and school misconduct. Journal of Youth and Adolescence, 41(4), 499 - 514. https://doi.org/10.1007/s10964-011-9674-2

Donat, M., Umlauft, S., Dalbert, C., \& Kamble, S. V. (2012). Belief in a just world, teacher justice, and bullying behavior. Aggressive Behavior, 38(3), 185 - 193. https://doi.org/10.1002/ab.21421

Eccles, J. S., \& Midgley, C. (1989). Stage/environment fit: Developmentally appropriate classrooms for early adolescents. In R. E. Ames \& C. Ames (Eds.), Research on motivation in education, Vol. 3 (pp. 139 - 186). San Diego, CA: Academic Press.

Eccles, J. S., \& Roeser, R. W. (2009). Schools, academic motivation, and stage-environment fit. In R. M. Lerner \& Steinberg (Eds.), Handbook of adolescent psychology, 3rd ed. (pp.404-434). Hoboken, NJ: John Wiley \& Sons.

Eccles, J. S., Wigfield, A., Midgley, C., Reuman, D., Maclver, D., \& Feldhaufer, H. (1993). Negative effects of traditional middle schools on students' motivation. The Elementary School Journal, 93(5), 553 - 574. https://doi.org/10.1086/461740

Eccles, J. S., \& Wang, M. T. (2012). Part I commentary: So what is student engagement anyway? In S. L. Christenson, A. L. Reschly, \& C. Wylie (Eds.), Handbook of research on student engagement (pp. 133 -148). New York, NY: Springer.

EDK. (2017). The Swiss education system. Retrieved from: http:// www.edk.ch

Eisenberg, N., Miller, P. A., Shell, R., McNalley, S., \& Shea, C. (1991). Prosocial development in adolescence: A longitudinal study. Developmental Psychology, 27(5), 849-857. https://doi.org/10. 2307/1131806

Enders, C. K. (2006). Analyzing structural equation models with missing data. In G. R. Hancock \& R. O. Mueller (Eds.), Structural Equation Modeling: A Second Course (pp.313-342). Greenwich, CT: Information Age Publishing.

Faul, F., Erdfelder, E., Lang, A.G., \& Buchner, A. (2007). G*Power 3: A flexible statistical power analysis program for the social, behavioral, and biomedical sciences. Behavior Research Methods, 39, 175-191.

Finn, J. D. (1989). Withdrawing from school. Review of Educational Research, 59(2), 117 - 142. https://doi.org/10.3102/003465430 59002117

Glanville, J. L., \& Wildhagen, T. (2007). The measurement of school engagement: Assessing dimensionality and measurement invariance across race and ethnicity. Educational and Psychological Measurement,67,1019-1041.https://doi.org/10.1177/0013164 406299126

Gniewosz, B., Eccles, J. S., \& Noack, P. (2012). Secondary school transition and the use of different sources of information for the construction of the academic self-concept. Social Development, 21(3), 537 - 557. https://doi.org/10.1111/j.1467-9507.2011.00635.x

Güroğlu, B., van den Bos, W., \& Crone, E. A. (2009). Fairness considerations: Increasing understanding of intentionality during adolescence. Journal of Experimental Child Psychology, 104(4), 398 - 409. https://doi.org/10.1016/j.jecp.2009.07.002

Hadjar, A., \& Lupatsch, J. (2010). Der Schul(miss)erfolg der Jungen. Kölner Zeitschrift für Soziologie und Sozialpsychologie, 62(4), 599-622. https://doi.org/10.1007/s11577-010-0116-z

Hagenauer, G., \& Hascher, T. (2014). Early adolescents' enjoyment experienced in learning situations at school and its relation to student achievement. Journal of Education and Training Studies, 2(2), 20 - 30. https://doi.org/10.11114/jets.v2i2.254

Hagenauer, G., Reitbauer, E., \& Hascher, T. (2013). "It's cool but challenging": The relevance of basic need fulfillment for students' school enjoyment and emotional experiences at the transition from primary to secondary education. Orbis Scholae, 7(2), 23 - 42. https://doi.org/0.14712/23363177.2015.19

Hascher, T. (2004). Wohlbefinden in der Schule. Münster: Waxmann Verlag.
Hascher, T., \& Hadjar, A. (2018). School alienation: Theoretical approaches and educational research. Educational Research, 60, 1 - 18. https://doi.org/10.1080/00131881.2018.1443021

Hascher, T., \&, Hagenauer, G. (2010). Alienation from school. International Journal of Educational Research, 49, 220 - 232. https:// doi.org/10.1016/j.ijer.2011.03.002

Hirschfeld, G., \& von Brachel, R. (2014). Multiple-Group confirmatory factor analysis in R-A tutorial in measurement invariance with continuous and ordinal indicators. Practical Assessment, Research \& Evaluation, 19(7), $1-12$.

Hu, L. T., \& Bentler, P. M. (1999). Cutoff criteria for fit indexes in covariance structure analysis: Conventional criteria versus new alternatives. Structural equation modeling: a multidisciplinaryjournal,6(1),1 - 55.https://doi.org/10.1080/10705519909540118

Jiang, R., Liu, R. D., Ding, Y., Zhen, R., Sun, Y., \& Fu, X. (2018). Teacher justice and students' class identification: Belief in a just world and teacher-student relationship as mediators. Frontiers in Psychology, 9: 802. https://doi.org/10.3389/fpsyg.2018.00802

Johnson, G. M. (2005). Student alienation, academic achievement, and WebCT use. Educational Technology and Society, 8(2), $179-189$.

Kaufman, R. (2011). A manager's pocket guide to strategic thinking and planning. Amherst, MA: HRD Press.

Legault, L., Green-Demers, I., \& Pelletier, L. (2006). Why do high school students lack motivation in the classroom? Journal of Educational Psychology, 98(3), 567 - 582. https://doi.org/10.1037/ 0022-0663.98.3.567

Mahmoudi, H., Brown, M. R., Saribagloo, J. A., \& Dadashzadeh, S. (2015). The role of school culture and basic psychological needs on Iranian adolescents' academic alienation. Youth \& Society, 50(1), 116 - 136. https://doi.org/10.1177/0044118X15593668

Malecki, C. K., \& Demaray, M. K. (2003). What type of support do they need? Investigating student adjustment as related to emotional, informational, appraisal, and instrumental support. School Psychology Quarterly, 18(3), 231-252. https://doi. org/10.1521/scpq.18.3.231.22576

Mann, S. J. (2001). Alternative perspectives on student learning. Studies in Higher Education, 26(1), 7 - 19. https://doi.org/10.1080/ 03075070020030689

Martin, J., Sokol, B. W., \& Elfers, T. (2008). Taking and coordinating perspectives: From prereflective interactivity, through reflective intersubjectivity, to metareflective sociality. Human Development, 51(5-6), 294-317. https://doi.org/10.1159/000170892

Marx, K. (1844). Estranged labour. In Economic and philosophic manuscripts of 1844: Marx-Engels Collected Works, Vol. 3, 1932.

Maslow, A. H. (1943). A theory of human motivation. Psychological review, 50(4), 370 - 396. https://doi.org/10.1037/h0054346

McClelland, D. C. (1961). The Achieving Society. New York: Van Nostrand Reinhold.

McGee, C., Ward, R., Gibbons, J., \& Harlow, A. (2003). Transition to secondary school: A literature review. Report to the Ministry of Education. New Zealand: The Ministry of Education.

Midgley, C., Feldhaufer, H., \& Eccles, J. S. (1988). The transition to junior high school: Beliefs of pre-and post-transition teachers. Journal of Youth and Adolescence, 17(6), 543-562. https://doi. org/10.1007/BF01537831

Millsap, R. E. (2012). Statistical approaches to measurement invariance. New York: Routledge.

Morinaj, J., Scharf, J., Grecu, A., Hadjar, A., Hascher, T., \& Marcin, K. (2017). School alienation: A construct validation study. Frontline Learning Research, 5(2), 36-59. https://doi.org/10.14786/flr. v5i2.298

Müller, F., \& Thomas, A. (2011). Skalen zur wahrgenommenen Basic Needs Unterstützung von Schüler/innen, Klagenfurt: Institut für Unterrichts - und Schulentwicklung. Alpen-Adria-UniversitätKlagenfurt. 
Murdock, T. B. (1999). The social context of risk. Journal of Educational Psychology, 91(1), 62 - 75. https://doi.org/10.1037/00220663.91.1.62

Murray, H. A. (1938). Explorations in Personality. New York: Oxford University Press.

Muthén, L. K., and Muthén, B. O. (1998-2012). Mplus user's guide (7th ed.). Los Angeles, CA: Muthén \& Muthén.

Newman, B. M., \& Newman, P. R. (2003). Development through life (8th ed.). Belmont, CA: Wadsworth.

Niemiec, C. P., \& Ryan, R. M. (2009). Autonomy, competence, and relatedness in the classroom: Applying self-determination theory to educational practice. School Field, 7(2), 133 -144. https://doi.org/10.1177/1477878509104318

OECD. (2004). Learning for tomorrow's world. Paris, France: OECD Publishing.

OECD. (2017). PISA 2015 results (Volume III): Students' well-being. Paris: OECD Publishing. https://doi.org/10.1787/9789264273856-en

Osterman, K. F. (2000). Students' need for belonging in the school community. Review of Educational Research, 70(3), 323-367. https://doi.org/10.3102/00346543070003323

Peter, F., Donat, M., Umlauft, S., \& Dalbert, C. (2013). Einführung in die Gerechtigkeitspsychologie. In C. Dalbert (Hrs.), Gerechtigkeit in der Schule (S.11-28). Wiesbaden, Deutschland: Springer VS.

Pretsch, J., Ehrhardt, N., Engl, L., Risch, B., Roth, J., Schumacher, S., \& Schmitt, M. (2016). Injustice in school and students' emotions, wellbeing, and behavior: A longitudinal study. Social Justice Research, 29(1),119-138. https://doi.org/10.1007/s11211-015-0234-x

Rauer, W., \& Schuck, K. D. (2003). FEESS 3-4: Fragebogen zur Erfassung emotionaler und sozialer Schulerfahrungen von Grundschulkindern dritter und vierter Klassen: Manual. Beltz Test.

Reeve, J. (2012). A self-determination theory perspective on student engagement. In S.L. Christenson, A. L. Reschly, \& C. Wylie (Eds.), Handbook of research on student engagement (pp.149-172). New York, NY: Springer. https://doi. org/10.1007/978-1-4614-2018-7_7

Reilly, R. C., \& Mitchell, S. N. (2010). The clash of the paradigms: Tracking, cooperative learning, and the demolition of the zone of proximal development. Alberta Journal of Educational Research, 56(4), $419-435$.

Resh, N., \& Sabbagh, C. (2014). Sense of justice in school and civic attitudes. Social Psychology of Education, 17(1), 51 - 72. https:// doi.org/10.1007/s11218-013-9240-8

Ryan, R. M., \& Deci, E. L. (2000). Intrinsic and extrinsic motivations: Classic definitions and new directions. Contemporary Educational Psychology,25(1),54-67.https://doi.org/10.1006/ceps.1999.1020

Ryan, R. M., \& Deci, E. L. (2017). Self-determination theory: Basic psychological needs in motivation, development, and wellness. Guilford Publications.

Satorra, A., \& Bentler, P. M. (2001). A scaled difference chi-square test statistic for moment structure analysis. Psychometrika, 66, 507 - 514. https://doi.org/10.1007/BF02296192

Schermelleh-Engel, K., Moosbrugger, H., \& Müller, H. (2003). Evaluating the fit of structural equation models: Tests of significance and descriptive goodness-of-fit measures. Methods of Psychological Research Online, 8(2), $23-74$.

Skues, J. L., Cunningham, E. G., \& Pokharel, T. (2005). The influence of bullying behaviours on sense of school connectedness, motivation and self-esteem. Journal of Psychologists and Counsellors in Schools, 15(1), 17-26. https://doi.org/10.1375/ ajgc.15.1.17

Steenkamp, J. B. E., \& Baumgartner, H. (1998). Assessing measurement invariance in cross-national consumer research. Journal of ConsumerResearch,25(1),78-90.https://doi.org/10.1086/209528

Steinberg, L. (2005). Cognitive and affective development in adolescence. Trends in Cognitive Sciences, 9(2), 69-74. https://doi. org/10.1016/j.tics.2004.12.005
Stern, M. (2012). Evaluating and promoting positive school attitude in adolescents. New York, NY: Springer. https://doi.org/10.1007/978$1-4614-3427-6$

Symonds, J., \& Hargreaves, L. (2016). Emotional and motivational engagement at school transition: A qualitative stage-environment fit study. The Journal of Early Adolescence, 36(1), 54-85. https://doi.org/10.1177/0272431614556348

Tarquin, K., \& Cook-Cottone, C. (2008). Relationships among aspects of student alienation and self-concept. School Psychology Quarterly, 23(1), 16 - 25. https://doi.org/10.1037/10453830.23.1.16

Taylor, A.J. W. (2017). Affirming the importance of justice as a basic human need. Journal of Psychology and Cognition, 2(1).

Tyler, T. R., \& Blader, S. L. (2003). The group engagement model: Procedural justice, social identity, and cooperative behavior. Personality and social psychology review, 7(4), 349-361.

Vandenberg, R. J., \& Lance, C. E. (2000). A review and synthesis of the measurement invariance literature: Suggestions, practices, and recommendations for organizational research. Organizational research methods, 3(1), 4-70. https://doi.org/10.1177/10944281 0031002

van Ophuysen, S. (2008). Zur Veränderung der Schulfreude von Klasse 4 bis 7 . Eine Längsschnittanalyse Schulformspezifischer Effekte von Ferien und Grundschulübergang. Zeitschrift Für Pädagogische Psychologie, 22(3-4), 293 -306. https://doi. org/10.1024/1010-0652.22.34.293

Van Prooijen, J. W. (2009). Procedural justice as autonomy regulation. Journal of Personality and Social Psychology, 96(6), 1166-1180. https://doi.org/10.1037/a0014153

Wang, M. T., \& Eccles, J.S. (2012). Adolescent behavioral, emotional, and cognitive engagement trajectories in school and their differential relations to educational success. Journal of Research on Adolescence, 22(1),31-39. https://doi.org/10.1111/j.1532-7795. 2011.00753.x

Watkins, R., \& Kavale, J. (2014). Needs: Defining what you are assessing. New Directions for Evaluation, 2014(144), $19-31$.

Watt, H. M. (2004). Development of adolescents' self-perceptions, values, and task perceptions according to gender and domain in 7th-through 11th-grade Australian students. Child development, 75(5), 1556 -1574. https://doi.org/10.1111/j.1467-8624. 2004.00757.x

Wigfield, A., \& Eccles, J. S. (2000). Expectancy-value theory of achievement motivation. Contemporary educational psychology, 25(1), 68 -81. https://doi.org/10.1006/ceps.1999.1015

Wigfield, A., Eccles, J. S., Yoon, K. S., Harold, R. D., Arbreton, A. J., Freedman-Doan, C., \& Blumenfeld, P. C. (1997). Change in children's competence beliefs and subjective task values across the elementary school years: A 3-year study. Journal of educational psychology, 89(3), 451. https://doi.org/10.1037/ 0022-0663.89.3.451

\section{History/Historie}

Received Nov 27, 2017

Accepted after revision May 15, 2019

\section{Kaja Marcin}

Universität Bern

Institut für Erziehungswissenschaft

Fabrikstrasse 8

3012 Bern

Schweiz

kaja.marcin@gymneufeld.ch 